\title{
Effectiveness of WeChat for Improving Exclusive Breastfeeding in Huzhu County China: Randomized Controlled Trial
}

Qiong Wu ${ }^{1}, \mathrm{MSc}$; Yiwen Huang ${ }^{1}$, MSc; Zijun Liao ${ }^{1}, \mathrm{PhD}$; Michelle Helena van Velthoven ${ }^{2}, \mathrm{PhD}$; Wei Wang ${ }^{1}$, MSc; Yanfeng Zhang ${ }^{1}$, MSc

${ }^{1}$ Capital Institute of Pediatrics, Beijing, China

${ }^{2}$ University of Oxford, Oxford, United Kingdom

Corresponding Author:

Yanfeng Zhang, MSc

Capital Institute of Pediatrics

No. 2 Yabao Road

Chaoyang District

Beijing, 100020

China

Phone: 861085695554

Fax: 861085622025

Email: summyzh@126.com

\section{Abstract}

Background: The benefits of breastfeeding for both infants and mothers have been well recognized. However, the exclusive breastfeeding rate in China is low and decreasing. Mobile technologies have rapidly developed; communication apps such as WeChat (one of the largest social networking platforms in China) are widely used and have the potential to conveniently improve health behaviors.

Objective: This study aimed to assess the effectiveness of using WeChat to improve breastfeeding practices.

Methods: This 2-arm randomized controlled trial was conducted among pregnant women from May 2019 to April 2020 in Huzhu County, Qinghai Province, China. Pregnant women were eligible to participate if they were aged 18 years or older, were 11 to 37 weeks pregnant with a singleton fetus, had no known illness that could limit breastfeeding after childbirth, used WeChat through their smartphone, and had access to the internet. A total of 344 pregnant women were recruited at baseline, with 170 in the intervention group and 174 in the control group. Women in the intervention group received breastfeeding knowledge and promotion information weekly through a WeChat official account from their third month of pregnancy to 6 months postpartum. The primary outcome of exclusive and predominant breastfeeding rate was measured 0-1 month, 2-3 months, and 4-5 months postpartum.

Results: At 0-1 month postpartum, the exclusive breastfeeding rate was significantly higher in the intervention group than that in the control group (81.1\% vs $63.3 \%$; odds ratio [OR] 2.75, 95\% CI 1.58-4.78; $P<.001)$. Similarly, mothers in the intervention group were more likely to provide predominantly breast milk (OR $2.77,95 \%$ CI $1.55-4.96 ; P<.001)$ and less likely to give dairy products to their children (OR $0.40,95 \%$ CI $0.21-0.75 ; P=.005)$. There was no statistically significant difference for exclusive breastfeeding rate 2-3 months $(P=.09)$ and 4-5 months postpartum $(P=.27)$, though more children in the intervention group were exclusively breastfed than those in the control group 2-3 months postpartum (intervention: 111/152, 73.0\%; control: $96 / 152$, 63.2\%) and 4-5 months postpartum(intervention: 50/108, 46.3\%; control: 46/109, 42.2\%).

Conclusions: This study is the first effort to promote exclusive breastfeeding through WeChat in China, which proved to be an effective method of promoting exclusive breastfeeding in early life. WeChat health education can be used in addition to local breastfeeding promotion programs.

Trial Registration: Chinese Clinical Trial Registry ChiCTR1800017364; http://www.chictr.org.cn/showproj.aspx?proj=29325 International Registered Report Identifier (IRRID)： RR2-10.1186/s12889-019-7676-2

(J Med Internet Res 2020;22(12):e23273) doi: 10.2196/23273 


\section{KEYWORDS}

breastfeeding; exclusive breastfeeding; WeChat; mHealth; randomized controlled trial

\section{Introduction}

Appropriate child feeding is the foundation for good nutritional intake and healthy development and is a critical factor for health in adults [1-3]. As a part of optimal feeding practices, exclusive breastfeeding is recognized as a cornerstone of child survival and health, by providing essential irreplaceable nutrition for a child's growth and development [4]. Therefore, the World Health Organization (WHO) and United Nations Children's Fund (UNICEF) recommend that children should be exclusively breastfed from birth to 6 months of age and continually breastfed until they are 2 years old or older [5]. Moreover, one of the WHO global nutrition targets for 2025 is increasing the exclusive breastfeeding rate in the first 6 months of life to at least $50 \%$ [4].

In China, the exclusive breastfeeding rate for under 6 months of age is a concern and achieving the 2025 global target remains an ongoing challenge. According to the Chinese national data, the exclusive breastfeeding rate under 6 months was $27.6 \%$ in 2008 [6] and $20.7 \%$ in 2013 (the weighted exclusive breastfeeding rate was $18.6 \%$ ) [7], which showed a downward trend. Therefore, much effort is required to explore effective ways to control this downward trend, and hence, to promote breastfeeding in China.

Positive breastfeeding outcomes are usually related to the improvement of maternal breastfeeding knowledge and attitudes $[2,8]$. Although interventions on breastfeeding promotion vary worldwide, education and support are the 2 most common approaches, and interventions on exclusive breastfeeding containing these 2 elements have mixed success $[9,10]$. In China, breastfeeding education is generally implemented through the rural 3-tier health care system (county-township-village) at antenatal and postnatal care [11]. Since 2009, China has been implementing a national program called Basic Public Health Service, in which health care workers are required to provide face-to-face breastfeeding and complementary feeding counseling to pregnant women and mothers throughout antenatal and postnatal care [11]. However, research has indicated that mothers in rural areas rarely receive feeding information from health facilities; their main sources of information were family members and friends, who were unlikely to have access to better information and may have misinformed mothers [12-14]. Therefore, new channels are needed in rural China to deliver effective infant feeding education.

With the widespread use of smartphones, using apps in the health sector for delivering health care services and health promotion is an increasing phenomenon [15-19]. In China, one of the most popular smartphone apps is WeChat, which offers services such as Facebook, Twitter, WhatsApp, and others, on a single platform. More than 1.32 billion users were registered with WeChat throughout the world by Q2 2019, and more than 1.15 billion people were monthly active users [20]. Approximately 45 billion messages are exchanged on the platform every day [20]. Furthermore, there is an app-within-an-app platform in WeChat called WeChat Official Accounts, which can be used for individuals, governments, media organizations, and business enterprises to communicate and interact with their subscribers and provide them with services through text, images, voice, videos, and rich-media messages [21]. There were more than 20 million registered WeChat official accounts at the end of 2018 [20]. WeChat is gradually changing the channels through which people receive information and has been used as a communication tool to change health behaviors, showing potential positive impacts on disease management of cancer [22], malaria [23], asthma [24], chronic rhinosinusitis [25], diabetes [26], and weight loss [27]. However, no studies have focused on using WeChat to support caregivers with infant and young child feeding. The objective of this randomized controlled trial was to evaluate the effectiveness of a WeChat breastfeeding intervention on promoting exclusive breastfeeding in rural areas of China.

\section{Methods}

\section{Study Design}

A 2-arm randomized controlled trial (Chinese Clinical Trial Registry ChiCTR1800017364) was conducted between May 9, 2019 and April 3, 2020. We aimed to evaluate the effectiveness of using a WeChat account for improving exclusive breastfeeding of children aged 0-5 months. The protocol for this randomized controlled trial was previously published [28]. The sampling unit was individual pregnant women, who were randomized to routine antenatal and postnatal care or routine care plus the WeChat breastfeeding education.

\section{Study Sites and Context}

This trial was carried out in 13 townships in Huzhu County, Qinghai Province, China. Qinghai Province is in northwest China, with a total population of 6,078,200 in 2019. Huzhu County lies in the northeast of Qinghai province and has a total population of 401,540 [29]. There were 91,321 women of reproductive age and 4325 pregnant women in Huzhu County in 2017 (Huzhu County Maternal and Child Health Family Planning Service Centre).

Huzhu County has 19 townships and 294 villages. We excluded 6 townships; 4 townships had already been selected by another maternal and child health project, and the other 2 were remote with a small number of pregnant women.

\section{Participants and Recruitment}

Pregnant women were eligible to participate in this trial if they were aged at least 18 years, were 11-37 weeks pregnant with a singleton fetus, had no known illness that limits breastfeeding after childbirth, were able to read and communicate in Mandarin, used WeChat through their smartphone, and had access to the internet. The exclusion criteria were (1) pregnant women who did not come to the township hospitals to participate in the trial; (2) pregnant women with severe disease and complications of pregnancy or HIV; (3) women who had a miscarriage or stillbirth; (4) mothers with infants with a low birth weight 
$(<2500 \mathrm{~g})$ or who were born prematurely $(<37$ weeks of gestation).

Before recruitment, we asked each township hospital to provide a list of the names of all pregnant women between 11 to 37 weeks' gestation, which included information on gestational age, gravidity, and parity. A total of 444 women were listed. Based on this list, participating pregnant women were invited to come to their township hospitals and were given full information about the study between May 9, 2019 and May 17, 2019. After agreeing to participate and signing the written consent form, a researcher gave each eligible pregnant woman an opaque sealed envelope, which included a random number generated in advance and indicated the allocated group. After completing baseline data collection, all the eligible participants were randomized to either the WeChat intervention group or the control group at a 1:1 ratio.

\section{Sample Size Calculation}

The sample size for this study was estimated using a 0-5 months of age exclusive breastfeeding rate of $29.2 \%$ from a pilot cross-sectional survey conducted by our team in Datong County in Qinghai in September 2017. We expected to achieve a 20\% increase in the exclusive breastfeeding rate with the WeChat intervention. Assuming a power of $80 \%$ and a $5 \%$ significance level, we determined that a sample size of 93 pregnant women for each (intervention and control) group was needed for this study. To compensate for attrition and loss to follow-up, we planned to enroll 200 pregnant women in each group.

\section{Intervention Group}

Women in both intervention and control groups were asked to follow the WeChat account called Huzhu County Maternal and Child Health Family Planning Service Centre on their smartphone by scanning the 2D code at the back of random number cards. There was a special module called Ke Xue Wei Yang (Optimal Feeding) within the WeChat Official Account which was developed by an information technology company, ZYZY (Beijing) Pioneer of Cultural Essence Co Ltd and pretested in Huzhu County in Aug 2018 [28]. Pregnant women allocated to the intervention group were also asked to subscribe to and register with the Ke Xue Wei Yang module by entering information on their name, phone number, gestational age, expected date of delivery, village and county of residence and were provided a WeChat log-in and password. Pregnant women in the control group were not able to register with the Ke Xue Wei Yang module and did not have access to the information in the module, to preclude contamination between groups through direct sharing of messages sent via WeChat.

There were 4 components in the Ke Xue Wei Yang module: feeding messages, a feeding knowledge competition, a baby growth chart, and an online forum (Figure 1), which were described in detail in our protocol [28].

The feeding messages, the most important component, were designed for breastfeeding promotion education and provided key breastfeeding knowledge and relevant infant feeding advice, breastfeeding problems encountered for both mother and child, and preparation for both breastfeeding and complementary feeding. All messages were developed based on the WHO breastfeeding recommendations, guidelines, or published literature; messages were published before recruitment. Once women in the intervention group subscribed to the Ke Xue Wei Yang module, they could read all messages whenever they wanted. Furthermore, we considered that late pregnancy (37 weeks or above), the first month postpartum, and 4 months postpartum were 3 key stages for mothers and that breastfeeding information needed to be strengthened during these stages, so we sent an additional 3 sets of tailored messages to each pregnant woman and mother at these stages via WeChat on Monday, Wednesday, and Friday every week. Specifically, we sent information on getting ready for breastfeeding and key breastfeeding recommendations to women who were at least 37 weeks pregnant. For new mothers 1 month postpartum, we sent key breastfeeding recommendations and common breastfeeding problems encountered for both mother and child. We sent information on starting complementary feeding by 6 months of age to mothers whose children were 4 months or older (to avoid having mothers introduce complementary food too early or too late).

Women could participate in the feeding knowledge competition component to test their breastfeeding knowledge. Moreover, women could enter their children's weight and height in the baby growth chart component whenever they want to monitor their children's growth and ask breastfeeding related questions on the online forum component. 
Figure 1. The interface of the WeChat intervention: (a) log-in interface, (b) main interface, (c) feeding messages, (d) feeding competition, (e) baby growth chart, and (f) online forum.

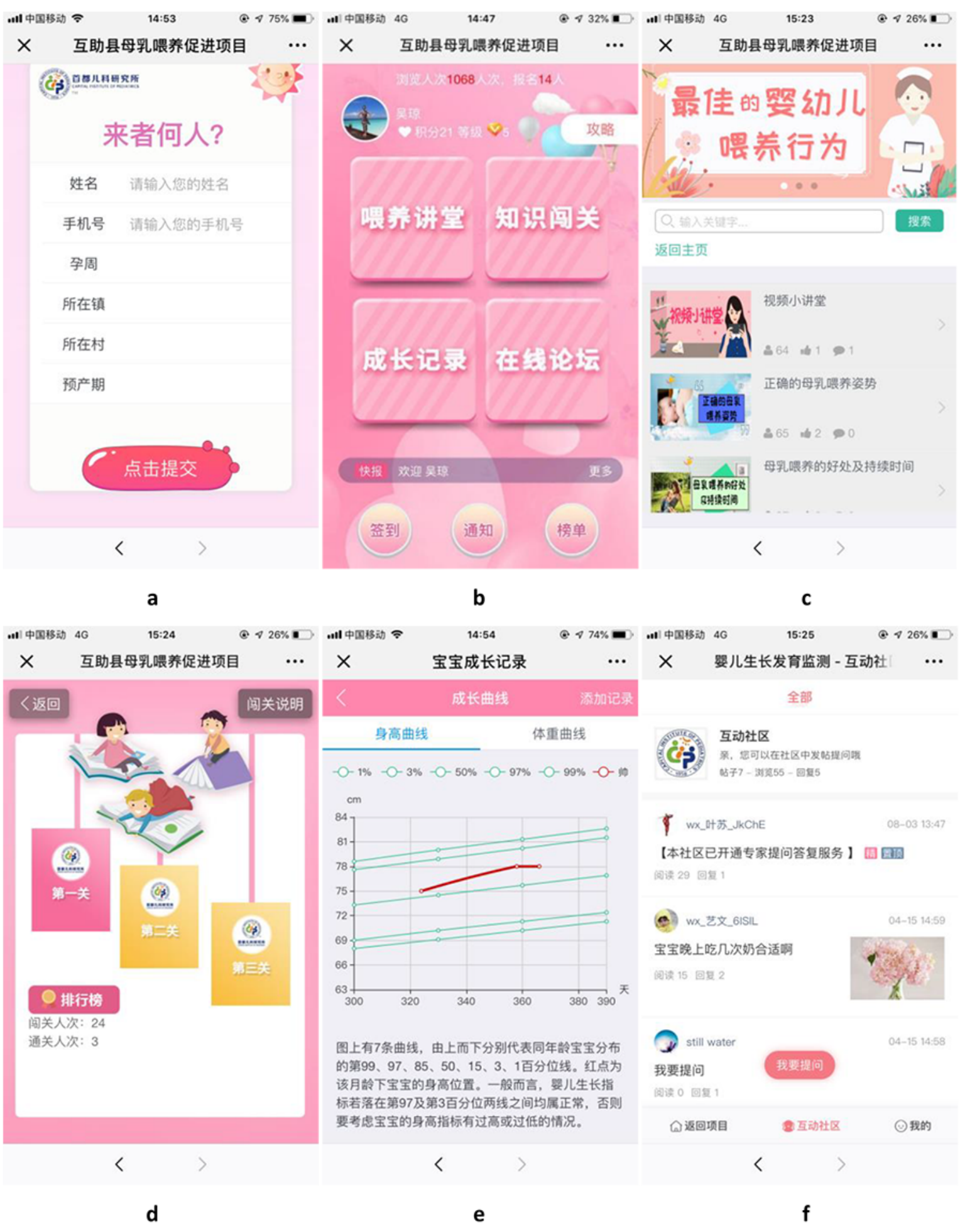

\section{Data Collection}

Data were collected by face-to-face at baseline and by telephone during follow-up interviews. Baseline data collection was carried out after the recruitment session. After receiving consent to participate, we interviewed the pregnant women (baseline questionnaire), which included information on demographic characteristics, antenatal care, hemoglobin levels, as well as breastfeeding knowledge. Baseline interviewers, who were from a vocational-technical school in Huzhu County and trained on interview methodology, used smartphones to collect the baseline data.

Follow-up interviews were conducted by telephone at $0-1$ months (mean 35.3 days, SD 10.5), 2-3 months (mean 102.7 days, SD 9.9), 4-5 months (mean 157.2 days, SD 17.8) postpartum. Data from women in both the intervention group 
and the control group were collected on breastfeeding knowledge, practices, reasons for weaning, and information channels by health workers form Huzhu County Maternal and Child Health Family Planning Service Centre, who were blinded to intervention status and trained on interview methodology by research staff from the Capital Institute of Pediatrics.

\section{Outcome Measurement}

The primary outcome measure was exclusive and predominant breastfeeding rate at 0-1 month (0-60 days), 2-3 months (61-120 days), and 4-5 months (121-180 days) postpartum in both the intervention group and the control group. Secondary outcomes included the following: (1) the proportion of early initiation of breastfeeding; (2) prelacteal feeding rate; (3) rate of any breastfeeding; (4) mothers' knowledge on breastfeeding practices; (5) other infant feeding practices (such as giving dairy or dairy products, water, semisolid, or solid foods at 3 follow-ups).

According to the WHO definition, exclusive breastfeeding is defined as an infant receiving only breast milk, no other liquids or solids, except oral rehydration solution, drops or syrups for vitamins, minerals supplementation, or medicine [30]; predominant breastfeeding permits partial substitution with water-based fluids; and early initiation of breastfeeding is when an infant is put to the mother's breast within 1 hour of birth [30]. Prelacteal feeding was defined as the newborn being provided any food except mother's milk before initiating breastfeeding; any breastfeeding included partial substitution with infant formula, other fluids, or solid foods.

\section{Data Management and Analysis}

We performed statistical analysis with SAS (version 9.2 for Windows; SAS Institute). We summarized baseline characteristics, follow-up infant feeding practices, and mother's infant feeding knowledge, as median and interquartile range (IQR) for continuous variables or as number and proportion for categorical variables. We estimated the homogeneity in baseline characteristics between groups using the Wilcoxon rank-sum test for nonparametric continuous variables, and chi-square or Fisher exact test for categorical variables. Multiple logistic regression models were used to estimate the effects of the intervention on breastfeeding rates between groups at the 3 follow-up points, controlling for parity at baseline, as the distribution of parity was different between the 2 groups. We also used chi-square tests to compare the differences in mother's infant feeding knowledge between groups at baseline and 3 follow-up points. Participants who dropped out or who were lost to follow-up during the postpartum period were excluded from analysis and are reported separately (Multimedia Appendix 1). A $P$ value <.05 was considered statistically significant.

\section{Ethics Statement}

This study was approved by the ethical committee of the Capital Institute of Pediatrics, Beijing, China. All women were given an information sheet, and participating women provided both verbal and written informed consent.

\section{Results}

\section{General}

We recruited 344 pregnant women. We randomized 170 to the intervention group and 174 to the control group between May 9, 2019 and May 17, 2019; 25 were excluded due to miscarriage, stillbirth, premature birth, or low birth weight, leaving 319 participants for analysis (161 in the intervention group and 158 in the control group). A total of 32,15 , and 8 participants could not be contacted by phone for unknown reasons at the first, second, and third follow-ups, respectively. Moreover, 94 mothers missed the follow-up deadline (children <180 days age) at the 4-5 months postpartum follow-up because of the long holiday of Chinese Lunar New Year and the coronavirus (COVID-19) outbreak in January 2020 in China. The CONSORT (Consolidated Standards of Reporting Trials) [31] flow diagram is shown in Figure 2. Most demographic characteristics were similar between the participants who dropped out and participants who were followed up (Multimedia Appendix 1). However, at the 0-1 month postpartum follow-up, more mothers who only attended primary school dropped out; at the 4-5 months postpartum follow-up, more mothers who had a higher gestational age at enrollment dropped out. 
Figure 2. CONSORT flow diagram. CONSORT: Consolidated Standards of Reporting Trials.

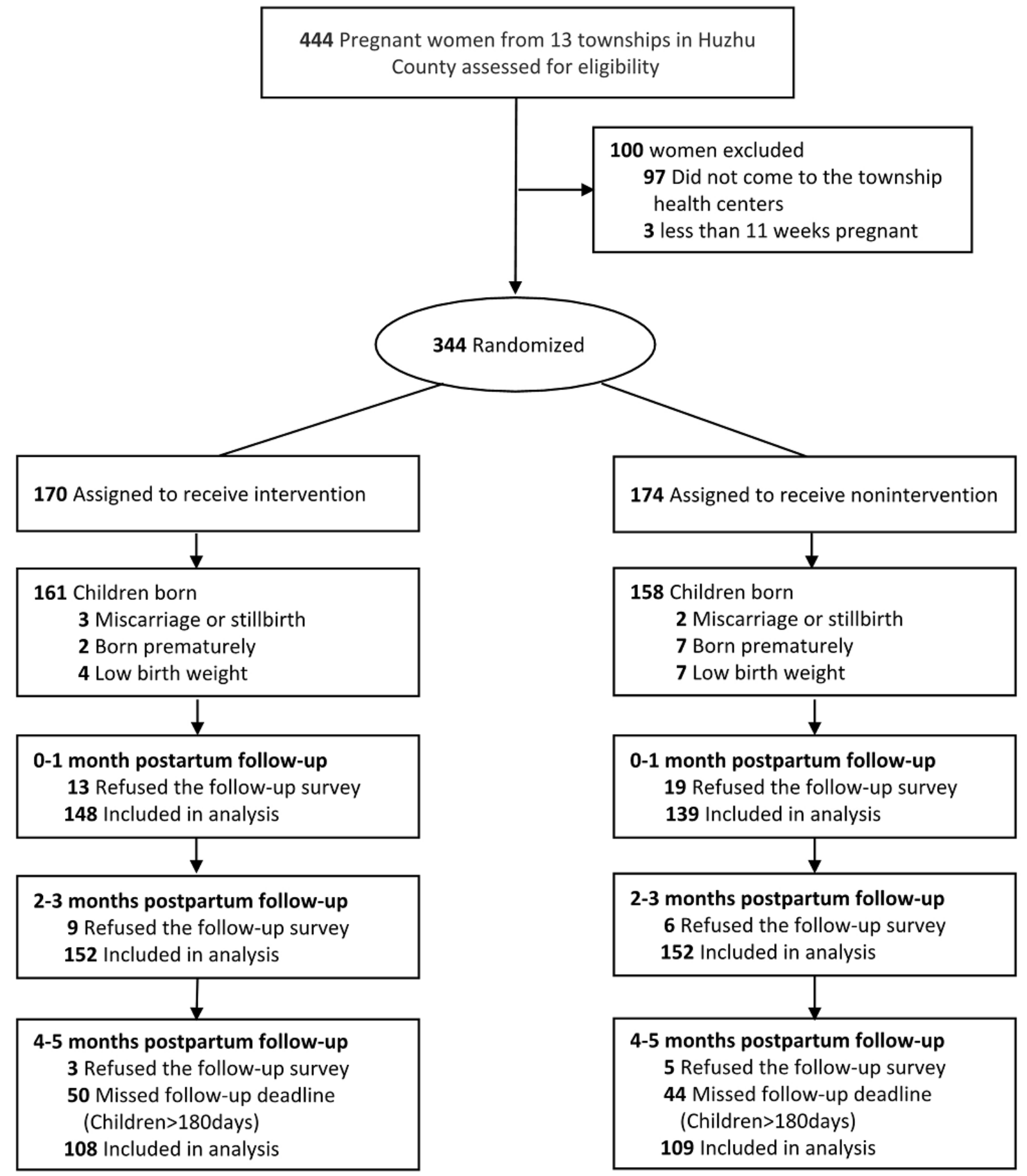

\section{Characteristics of the Participants}

The median age of enrolled participants was 28 years (IQR 25-31). There were no differences between the intervention and control groups for most demographic characteristics, except for gravidity and parity (Table 1). Compared with those in the control group, more participants in the intervention group had their first pregnancy (intervention: 46/161, 28.6\%; control: 26/158, 16.5\%; $P=.01$ ) or primipara (intervention: 48/161, 29.8\%; control: $28 / 158,17.7 \%$; $P=.01)$. The prevalence of maternal anemia was lower in the intervention group (64/161, $40.0 \%)$ than that in the control group $(72 / 158,45.6 \%)$, but the difference was not statistically significant $(P=.32)$. 
Table 1. Baseline characteristics of participants by treatment groups.

\begin{tabular}{|c|c|c|c|c|}
\hline Characteristics & Total $(\mathrm{N}=319), \mathrm{n}(\%)$ & WeChat group $(\mathrm{n}=161), \mathrm{n}(\%)$ & Control group $(\mathrm{n}=158), \mathrm{n}(\%)$ & $P$ value \\
\hline Age (years), median (IQR) & $28(25-31)$ & $28(24-31)$ & $28(25-31)$ & .45 \\
\hline Gestational age (weeks) & & & & .27 \\
\hline $11-27$ & $186(58.3)$ & $89(55.3)$ & $97(61.4)$ & \\
\hline $28-42$ & $133(41.7)$ & $72(44.7)$ & $61(38.6)$ & \\
\hline Gravidity & & & & .01 \\
\hline First pregnancy & $72(22.6)$ & $46(28.6)$ & $26(16.5)$ & \\
\hline Second pregnancy or more & $247(77.4)$ & $115(71.4)$ & $132(83.5)$ & \\
\hline Parity & & & & .01 \\
\hline Primipara & $76(23.8)$ & $48(29.8)$ & $28(17.7)$ & \\
\hline Multipara & $243(76.2)$ & $113(70.2)$ & $130(82.3)$ & \\
\hline Education level & & & & .62 \\
\hline Primary school or below & $54(16.9)$ & $24(14.9)$ & $30(19.0)$ & \\
\hline Middle school & $173(54.2)$ & $89(55.3)$ & $84(53.2)$ & \\
\hline High school or above & $92(28.9)$ & $48(29.8)$ & $44(27.8)$ & \\
\hline Occupation & & & & .75 \\
\hline Stay-at-home & $278(87.1)$ & $138(85.7)$ & $140(88.6)$ & \\
\hline Self-employed & $9(2.8)$ & $5(3.1)$ & $4(2.5)$ & \\
\hline Farmer & $5(1.6)$ & $2(1.3)$ & $3(1.9)$ & \\
\hline Others & $27(8.5)$ & $16(9.9)$ & $11(7.0)$ & \\
\hline Nationality & & & & .86 \\
\hline Han & $244(76.5)$ & $125(77.6)$ & $119(75.3)$ & \\
\hline $\mathrm{Tu}$ & $49(15.4)$ & $23(14.3)$ & $26(16.5)$ & \\
\hline Others & $13(8.1)$ & $13(8.1)$ & $13(8.2)$ & \\
\hline Ever received antenatal care & $252(79.0)$ & $121(75.2)$ & $131(82.9)$ & .12 \\
\hline Anemia & $136(42.8)$ & $64(40.0)$ & $72(45.6)$ & .32 \\
\hline
\end{tabular}

\section{WeChat Activity}

A total of 108 messages were published in the Ke Xue Wei Yang module in the WeChat official account, which was read more than 8892 times. The top 5 read messages were (1) benefits of breastfeeding (393 times); (2) importance of the early initiation (284 times); (3) breastfeeding positions and latching-on (242 times); (4) what is early initiation (214 times); (5) WHO recommendation: children should be exclusively breastfed from birth to 6 months (214 times).

\section{Breastfeeding Practice and Knowledge}

As illustrated in Table 2, nearly all children were breastfed in both groups. The early initiation rate was low (intervention: 93/148, 62.8\%; control: 101/139, 72.7\%); however, the difference was not statistically significant $(P=.08)$. In addition, approximately $40 \%$ of children were given prelacteal feeding in both groups, with $25.8 \%$ (74/287) given infant formula and $16.7 \%(48 / 287)$ given water. 
Table 2. Comparison of infant feeding practices.

\begin{tabular}{|c|c|c|c|c|c|c|}
\hline Indicators & Total $^{\mathrm{a}}$ & $\begin{array}{l}\text { Intervention } \\
\text { group }^{\mathrm{a}}\end{array}$ & $\begin{array}{l}\text { Control } \\
\text { group }^{\mathrm{a}}\end{array}$ & $P$ value & Odds ratio $(95 \% \mathrm{CI})$ & $\begin{array}{l}\text { Adjusted odds ratio } \\
(95 \% \mathrm{CI})^{\mathrm{b}}\end{array}$ \\
\hline First follow-up (0-1 month) & $287(100)$ & $148(100)$ & $139(100)$ & & & \\
\hline Early initiation & $194(67.6)$ & $93(62.8)$ & $101(72.7)$ & .11 & $0.64(0.39-1.05)$ & $0.66(0.40-1.09)$ \\
\hline Ever breastfeeding & $283(98.6)$ & 147 (99.3) & $136(97.8)$ & .30 & $3.24(0.33-31.54)$ & $3.42(0.34-34.4)$ \\
\hline Prelacteal feeding & $122(42.5)$ & $59(39.9)$ & $63(45.3)$ & .28 & $0.80(0.50-1.28)$ & $0.77(0.48-1.24)$ \\
\hline Giving formula & $74(25.8)$ & $37(25.0)$ & 37 (26.6) & $\mathrm{N} / \mathrm{A}^{\mathrm{c}}$ & N/A & N/A \\
\hline Giving water & $48(16.7)$ & $22(14.9)$ & $26(18.7)$ & N/A & N/A & N/A \\
\hline Exclusive breastfeeding & $208(72.5)$ & $120(81.1)$ & $88(63.3)$ & $<.001$ & $2.49(1.45-4.25)$ & $2.75(1.58-4.78)$ \\
\hline Predominant breastfeeding & $218(76.0)$ & $124(83.8)$ & $94(67.6)$ & $<.001$ & $2.47(1.41-4.34)$ & $2.77(1.55-4.96)$ \\
\hline Any breastfeeding & $279(97.2)$ & $146(98.6)$ & $133(95.7)$ & .18 & $3.29(0.65-16.59)$ & $3.09(0.61-15.79)$ \\
\hline Giving water during the past 24 hours & $17(5.9)$ & $6(4.1)$ & $11(7.9)$ & .17 & $0.49(0.18-1.34)$ & $0.49(0.17-1.35)$ \\
\hline $\begin{array}{l}\text { Giving dairy or dairy products during } \\
\text { the past } 24 \text { hours }\end{array}$ & $55(19.2)$ & $20(13.5)$ & $35(25.2)$ & .005 & $0.46(0.25-0.85)$ & $0.40(0.21-0.75)$ \\
\hline $\begin{array}{l}\text { Giving semisolid or solid foods during } \\
\text { the past } 24 \text { hours }\end{array}$ & $2(0.7)$ & $2(1.4)$ & 0 & .17 & N/A & N/A \\
\hline Second follow-up (2-3 months) & $304(100)$ & $152(100)$ & $152(100)$ & & & \\
\hline Exclusive breastfeeding & $207(68.1)$ & $111(73.0)$ & $96(63.2)$ & .09 & $1.47(0.91,2.38)$ & $1.53(0.94,2.49)$ \\
\hline Predominant breastfeeding & $212(69.7)$ & $113(74.3)$ & $99(65.1)$ & .07 & $1.55(0.95,2.54)$ & $1.60(0.96,2.64)$ \\
\hline Any breastfeeding & $287(94.4)$ & $144(94.7)$ & $143(94.1)$ & .64 & $1.13(0.43-3.02)$ & $1.27(0.47-3.46)$ \\
\hline Giving water during the past 24 hours & $11(3.6)$ & $3(2.0)$ & $8(5.3)$ & .18 & $0.36(0.09-1.39)$ & $0.40(0.10-1.55)$ \\
\hline $\begin{array}{l}\text { Giving dairy or dairy products during } \\
\text { the past } 24 \text { hours }\end{array}$ & $66(21.7)$ & $28(18.4)$ & $38(25.0)$ & .14 & $0.68(0.39-1.18)$ & $0.66(0.38-1.15)$ \\
\hline $\begin{array}{l}\text { Giving semisolid or solid foods during } \\
\text { the past } 24 \text { hours }\end{array}$ & $5(1.6)$ & $2(1.3)$ & $3(2.0)$ & .54 & $0.66(0.10-4.02)$ & $0.56(0.09-3.56)$ \\
\hline Third follow-up (4-5 months) & $217(100)$ & $108(100)$ & $109(100)$ & & & \\
\hline Exclusive breastfeeding & $96(44.2)$ & $50(46.3)$ & $46(42.2)$ & .27 & $1.18(0.69-2.02)$ & $1.37(0.78-2.39)$ \\
\hline Predominant breastfeeding & $111(51.2)$ & $58(53.7)$ & $53(48.6)$ & .20 & $1.23(0.72-2.09)$ & $1.46(0.82-2.51)$ \\
\hline Any breastfeeding & $198(91.2)$ & $101(93.5)$ & $97(89.0)$ & .10 & $1.78(0.68-4.72)$ & $2.34(0.84-6.54)$ \\
\hline Giving water during the past 24 hours & $27(12.4)$ & $12(11.1)$ & $15(13.8)$ & .63 & $0.78(0.34-1.76)$ & $0.82(0.36-1.87)$ \\
\hline $\begin{array}{l}\text { Giving dairy or dairy products during } \\
\text { the past } 24 \text { hours }\end{array}$ & $62(28.6)$ & $28(25.9)$ & $34(31.2)$ & .12 & $0.77(0.43-1.39)$ & $0.61(0.32-1.14)$ \\
\hline $\begin{array}{l}\text { Giving semisolid or solid foods during } \\
\text { the past } 24 \text { hours }\end{array}$ & $49(22.6)$ & $25(23.2)$ & $24(22.0)$ & .94 & $1.07(0.56-2.02)$ & $1.02(0.53-1.96)$ \\
\hline
\end{tabular}

${ }^{\mathrm{a}}$ The number of participants varied because of loss to follow-up.

${ }^{b}$ Multiple logistic regression controlled for baseline parity.

${ }^{\mathrm{c}} \mathrm{N} / \mathrm{A}$ : not applicable.

There was a downward trend for exclusive breastfeeding, predominant feeding, and any breastfeeding across the 3 follow-ups. At the 0-1 month postpartum follow-up, the exclusive breastfeeding rate was significantly higher in the intervention group $(120 / 148,81.1 \%)$ than in the control group $(88 / 139,63.3 \%)$, with an odds ratio (OR) of 2.75 (95\% CI $1.58-4.78 ; P<.001)$. Similarly, mothers in the intervention group were more likely to provide breast milk predominantly (intervention: 124/148, 83.8\%; control: 94/139, 67.6\%; OR $2.77,95 \%$ CI $1.55-4.96 ; P<.001)$, and less likely to give dairy or dairy products to their children (intervention: 20/148, 13.5\%; control: 35/139, 25.2\%; OR 0.40, 95\% CI 0.21-0.75; $P=.005$ ).

At the 2-3 months postpartum follow-up, exclusive breastfeeding (intervention: 111/152, 73.0\%; control: 96/152, 63.2\%) and predominant feeding (intervention: 113/152, 74.3\%; control: $99 / 152,65.1 \%$ ) in the intervention group were higher than in the control group, and fewer children were given dairy or dairy products in the intervention group (intervention: 28/152, 18.4\%; control: 38/152, 25.0\%). However, the differences between the 2 groups were not statistically significant $(P=.09$ for exclusive 
breastfeeding, $P=.07$ for predominant feeding, and $P=.14$ for giving dairy or dairy products).

At 4-5 months postpartum, both the rates of exclusive breastfeeding and predominant feeding dropped to $44.2 \%$ (96/217) and 51.2\% (111/217), respectively, and the proportion of children who were given dairy or dairy products increased to $28.6 \%(62 / 217)$ for both groups; there were no significant differences between the 2 groups $(P=.27$ for exclusive breastfeeding, $P=.20$ for predominant feeding, and $P=.12$ for giving dairy or dairy products).

At the first 2 follow-ups, the rate of any breastfeeding was quite high, whereas very few children were given water and semisolid or solid foods. However, any breastfeeding dropped to around $90 \%$ and the proportion of children who were given water and semisolid or solid foods increased to $12.4 \%$ (27/217) and $22.6 \%$ (49/217), respectively, 4-5 months postpartum. There were no significant differences between the 2 groups (0-1 month postpartum: $P=.18$ for any breastfeeding rate, $P=.17$ for giving water, and $P=0.17$ for giving semisolid or solid foods; $2-3$ months postpartum: $P=.64$ for any breastfeeding rate, $P=.18$ for giving water, and $P=.54$ for giving semisolid or solid foods; $4-5$ months postpartum: $P=.10$ for any breastfeeding rate, $P=.63$ for giving water, and $P=.94$ for giving semisolid or solid foods).

Table 3 shows that all feeding knowledge indicators were low at baseline, with $33.9 \%(108 / 319)$ knowing early initiation of breastfeeding, 28.8\% (92/319) knowing the duration of exclusive breastfeeding, $1.3 \%$ (4/319) knowing continued breastfeeding until 2 years of age, and 61.8\% (197/319) knowing introduction of complementary foods at 6-8 months in both groups. Mothers' feeding knowledge was greatly improved at follow-ups $(P<.001)$. However, there were no differences between the intervention group and the control group in baseline and each follow-up. The proportion of pregnant women who ever received breastfeeding information during pregnancy in both groups increased dramatically from only $25.7 \%(82 / 319)$ at baseline to more than $80 \%-90 \%$ of mothers who ever received breastfeeding information during pregnancy or after delivery $(P<.001)$, however, there was also no difference between the 2 groups (0-1 month postpartum: $P=.24,2-3$ months postpartum: $P=.63$, 4-5 months postpartum: $P=.09$ ). In addition, $16.3 \%$ $(52 / 319)$ of pregnant women reported having ever received infant formula information during their pregnancy. 
Table 3. Comparison of infant feeding knowledge between the intervention and control groups.

\begin{tabular}{|c|c|c|c|c|c|c|}
\hline \multirow[t]{2}{*}{ Outcomes } & \multicolumn{3}{|l|}{ Groups } & \multicolumn{3}{|l|}{$P$ value } \\
\hline & All & Intervention & Control & $\begin{array}{l}\text { Intervention } \\
\text { vs control }\end{array}$ & $\begin{array}{l}\text { Intervention, } \\
\text { baseline vs } \\
\text { follow-up }\end{array}$ & $\begin{array}{l}\text { Control, } \\
\text { baseline vs } \\
\text { follow-up }\end{array}$ \\
\hline Baseline & $319(100)$ & $161(100)$ & $158(100)$ & & & \\
\hline Knowing early initiation of breastfeeding & $108(33.9)$ & $58(36.0)$ & $50(31.6)$ & .41 & $\mathrm{~N} / \mathrm{A}^{\mathrm{a}}$ & N/A \\
\hline Knowing the duration of exclusive breastfeeding & $92(28.8)$ & $47(29.2)$ & $45(28.5)$ & .89 & N/A & N/A \\
\hline Knowing continued breastfeeding until 2 years & $4(1.3)$ & $2(1.2)$ & $2(1.3)$ & .98 & N/A & N/A \\
\hline $\begin{array}{l}\text { Knowing introduction of complementary foods at 6-8 } \\
\text { months }\end{array}$ & $197(61.8)$ & $101(62.7)$ & $96(60.8)$ & .72 & N/A & N/A \\
\hline $\begin{array}{l}\text { Women ever received breastfeeding information during } \\
\text { pregnancy }\end{array}$ & $82(25.7)$ & $41(25.5)$ & $41(25.9)$ & .92 & N/A & N/A \\
\hline $\begin{array}{l}\text { Women ever received infant formula information } \\
\text { during pregnancy }\end{array}$ & $52(16.3)$ & $29(18.0)$ & $23(14.6)$ & .40 & N/A & N/A \\
\hline First follow-up (0-1 month) & $287(100)$ & $148(100)$ & $139(100)$ & & & \\
\hline Knowing early initiation of breastfeeding & $196(68.3)$ & $101(68.2)$ & $95(68.4)$ & .99 & $<.001$ & $<.001$ \\
\hline Knowing the duration of exclusive breastfeeding & $199(69.3)$ & $107(72.3)$ & $92(66.2)$ & .26 & $<.001$ & $<.001$ \\
\hline Knowing continued breastfeeding until 2 years & $47(16.4)$ & $24(16.2)$ & $23(16.6)$ & .94 & $<.001$ & $<.001$ \\
\hline $\begin{array}{l}\text { Knowing introduction of complementary foods at 6-8 } \\
\text { months }\end{array}$ & $240(83.6)$ & $123(83.1)$ & $117(84.2)$ & .81 & $<.001$ & $<.001$ \\
\hline $\begin{array}{l}\text { Women ever received breastfeeding information during } \\
\text { pregnancy or after delivery }\end{array}$ & $239(83.3)$ & $127(85.8)$ & $112(80.6)$ & .24 & $<.001$ & $<.001$ \\
\hline $\begin{array}{l}\text { Women ever received infant formula information } \\
\text { during pregnancy or after delivery }\end{array}$ & $14(4.9)$ & $9(6.1)$ & $5(3.6)$ & .33 & .001 & .001 \\
\hline Second follow-up (2-3 months) & $304(100)$ & $152(100)$ & $152(100)$ & & & \\
\hline Knowing early initiation of breastfeeding & $216(71.1)$ & $115(75.7)$ & $101(66.5)$ & .08 & $<.001$ & $<.001$ \\
\hline Knowing the duration of exclusive breastfeeding & $240(78.9)$ & $122(80.3)$ & $118(77.6)$ & .57 & $<.001$ & $<.001$ \\
\hline Knowing continued breastfeeding until two years & $86(28.3)$ & $44(28.9)$ & $42(27.6)$ & .80 & $<.001$ & $<.001$ \\
\hline $\begin{array}{l}\text { Knowing introduction of complementary foods at 6-8 } \\
\text { months }\end{array}$ & $262(86.2)$ & $136(89.5)$ & $126(82.9)$ & .10 & $<.001$ & $<.001$ \\
\hline $\begin{array}{l}\text { Women ever received breastfeeding information during } \\
\text { pregnancy or after delivery }\end{array}$ & $286(94.1)$ & $144(94.7)$ & $142(93.4)$ & .63 & $<.001$ & $<.001$ \\
\hline $\begin{array}{l}\text { Women ever received infant formula information } \\
\text { during pregnancy or after delivery }\end{array}$ & $10(3.3)$ & $3(2.0)$ & $7(4.6)$ & .20 & $<.001$ & .003 \\
\hline Third follow-up (4-5 months) & $217(100)$ & $108(100)$ & $109(100)$ & & & \\
\hline Knowing early initiation of breastfeeding & $171(78.8)$ & $84(77.8)$ & $87(79.8)$ & .71 & $<.001$ & $<.001$ \\
\hline Knowing the duration of exclusive breastfeeding & $194(89.4)$ & $94(87.0)$ & $100(91.7)$ & .26 & $<.001$ & $<.001$ \\
\hline Knowing continued breastfeeding until 2 years & $80(36.9)$ & $44(40.7)$ & $36(33.0)$ & .24 & $<.001$ & $<.001$ \\
\hline $\begin{array}{l}\text { Knowing introduction of complementary foods at 6-8 } \\
\text { months }\end{array}$ & $205(94.5)$ & $102(94.4)$ & $103(94.5)$ & .99 & $<.001$ & $<.001$ \\
\hline $\begin{array}{l}\text { Women ever received breastfeeding information during } \\
\text { pregnancy or after delivery }\end{array}$ & $208(95.9)$ & $101(93.5)$ & $107(98.2)$ & .09 & $<.001$ & $<.001$ \\
\hline $\begin{array}{l}\text { Women ever received infant formula information } \\
\text { during pregnancy or after delivery }\end{array}$ & $7(3.2)$ & $3(2.8)$ & $4(3.7)$ & .71 & $<.001$ & .004 \\
\hline
\end{tabular}

${ }^{\mathrm{a} N} / \mathrm{A}$ : not applicable. 


\section{Discussion}

\section{Principal Findings}

This is the first randomized controlled trial using WeChat to promote exclusive breastfeeding in rural China. This study showed that antenatal plus postnatal WeChat breastfeeding education was associated with higher rates of exclusive and predominant breastfeeding in the early postnatal period. Mothers in the WeChat group had 2.7 times the odds of exclusive and predominant breastfeeding during the first 2 months postpartum. We found that giving dairy or dairy products, water, and semisolid or solid foods were common reasons for nonexclusive breastfeeding and that giving dairy or dairy products was the predominant reason, with $19.2 \%$ (55/287), $21.7 \%$ (66/304), and $28.6 \%(62 / 217)$ of all children being given dairy or dairy products ( $0-1$ months, $2-3$ months, and 4-5 months postpartum, respectively). In addition, $25.8 \%$ of newborns (74/287) were given prelacteal infant formula, which can limit an infant's frequency of suckling and expose them to increased risk of infection [32]. Our study demonstrated that a WeChat intervention could significantly reduce dairy or dairy product supplementation in early life, and thus improve the exclusive breastfeeding rate. The proportion in the WeChat group giving dairy or dairy products $0-1$ month postpartum was significantly lower than those in the control group $(P=.005)$. Although there was no significant difference between the groups 2-3 months $(P=.14)$ or $4-5$ months postpartum $(P=.12)$, fewer children in the WeChat group were given dairy or dairy products.

Proportions of children who were given water were 5.9\% (17/287), 3.6\% (11/304), and 12.4\% (27/217) (0-1 months, 2-3 months, and 4-5 months postpartum, respectively), and no difference was found between the groups. Very few children were given semisolid or solid foods in the first 2 follow-ups; however, the proportion dramatically increased to $22.6 \%$ (49/217) 4-5 months postpartum. Similarly, for children being given water, we found no difference between groups at all 3 follow-ups. Therefore, the WeChat intervention in our study could significantly reduce dairy or dairy product supplementation.

\section{Comparison With Prior Work}

It has been demonstrated that information and communication systems, such as web platform, mobile apps, and SMS can be used to promote, educate, and support breastfeeding women, and offer effective means of improving breastfeeding outcomes [33,34]. From 2010 to 2012, a study in Shanghai using SMS to promote breastfeeding found that weekly messages on infant feeding from the third trimester to 12 months postpartum could improve the exclusive breastfeeding rate at 6 months (OR 2.67) but not at 4 months [35]. This explained that many mothers in China were unaware the new concept of exclusive breastfeeding to 6 months of age, and the SMS disseminated the information to mothers [35]. In contrast, the WeChat intervention in our study improved the exclusive breastfeeding rate during the first 2 months postpartum and mainly reduced infant formula instead of water and semisolid or solid food. One reason might be that, in the first 2 months of breastfeeding, mothers may encounter more breastfeeding problems such as perceived insufficient milk supply, breast engorgement, poor suckling technique (of the infant), and sore nipples, which are well-known predictors for early formula supplementation and breastfeeding cessation [36-38]. Therefore, sufficient professional breastfeeding information is needed to increase their breastfeeding confidence during this period. However, 2 months postpartum, mothers may face substantial pressure from family and social culture to introduce formula or to wean [39], which may explain the limited effect on breastfeeding behavior changes afterward.

Improvements in health outcomes rely on putting knowledge into practice; however, population studies have documented that there is a gap between expectations and the actual performance of behaviors in health care and prevention [40]. Compared with the baseline, mothers' feeding knowledge improved at the 3 follow-ups for both intervention and control groups in this study. Proportions of mothers knowing the duration of exclusive breastfeeding dramatically increased from $28.8 \%(92 / 319)$ at baseline to $69.3 \%(199 / 287), 78.9 \%$ (240/304), and 89.4\% (194/217) (0-1 months, 2-3 months, and 4-5 months postpartum, respectively). In contrast, the exclusive breastfeeding rate dropped from $72.5 \%$ (208/287, 0-1 month postpartum) to $44.2 \%$ (96/217, 4-5 months postpartum). This is in line with the findings of a previous study [41] that described implementing their breastfeeding promotion interventions in the face of "time and space burdens." In addition, no differences in mothers' knowledge were found between the 2 groups, as expected, throughout the study. The reason might be that although mothers in the control group had no access to our WeChat information, they still had various sources of feeding information, including health facilities, mass media, books, and the internet. Successful breastfeeding promotion needs not only education but also support $[9,10]$. Therefore, multichannel support, such as experts online, through mobilized community, and by health facilities, should also be given to mothers.

With the widespread use of WeChat, it has become a potential health promotion tool in China [22-27,42-44]. The WeChat intervention in our study, providing mothers with information on breastfeeding promotion, could improve breastfeeding practices. The results were in accordance with those of previous studies on weight loss [27] and malaria [23], both of which showed that participants' knowledge, attitudes, and practices were greatly changed via WeChat official accounts. Information on the benefits of breastfeeding, early initiation, breastfeeding positions, and latching-on were read most during the intervention period, which indicated that these themes were primarily concerned among mothers. However, the effect is unsustainable for a longer time. Therefore, future studies should focus on how to improve the sustainability of the effect.

\section{Limitations}

Our study had several limitations. First, as the Chinese Lunar Year and the COVID-19 outbreak occurred in January 2020 in China, interviewers could not conduct follow-up data collection during that time, which led to a total of 94 mother-child pairs missing the 4-5 months postpartum follow-up deadline (180 days). However, we compared the baseline demographic characteristics between the participants who dropped out and those who were followed up and did not find differences 
between 2 groups, except for gestational age. Second, given the popular use of WeChat, there are other WeChat official accounts on breastfeeding promotion, and we cannot guarantee that each participant in both groups did not receive breastfeeding knowledge from other sources during the intervention period. However, our randomized controlled trial design could limit such bias. Third, as the randomization unit was individual pregnant women, contamination may exist between intervention and control groups within the same township.

\section{Conclusions}

This health education intervention for promoting breastfeeding via WeChat official accounts was associated with the improvement of exclusive breastfeeding rate in early life. This health education intervention strategy can be used as a reference for local breastfeeding promotion programs, especially, in rural areas of western China where fewer high-quality health services are provided than in urban areas.

\section{Acknowledgments}

The study was funded by UNICEF. The authors wish to thank all colleagues from the Huzhu Maternal and Child Health and Family Planning Service Center for coordination, logistic arrangements, and conducting follow up interviews. We would also like to thank all students from the Qinghai Institute of Health Sciences for their hard work as baseline interviewers. In addition, we would like to thank ZYZY (Beijing) Pioneer of Cultural Essence Co Ltd for providing their expertise developing the enhanced WeChat platform. Finally, we are indebted to all the mothers who participated in our study.

\section{Authors' Contributions}

YZ, QW, MV, WW, and YH designed the study; YZ, QW, and YH developed the intervention and contributed to implementing the study; YH conducted data collection; QW, YH, ZL, and WW analyzed and interpreted data. QW wrote the first draft of the manuscript, which was substantially revised by YZ, WW, MV, and ZL; all authors read and approved the final manuscript.

\section{Conflicts of Interest}

None declared.

\section{Multimedia Appendix 1}

Comparison of characteristics between participants with complete and incomplete data.

[DOCX File, 18 KB-Multimedia Appendix 1]

\section{Multimedia Appendix 2}

CONSORT-EHEALTH checklist (V 1.6.1).

[PDF File (Adobe PDF File), 11107 KB-Multimedia Appendix 2]

\section{References}

1. Black RE, Victora CG, Walker SP, Bhutta ZA, Christian P, de Onis M, Maternal Child Nutrition Study Group. Maternal and child undernutrition and overweight in low-income and middle-income countries. Lancet 2013 Aug 03;382(9890):427-451. [doi: 10.1016/S0140-6736(13)60937-X] [Medline: 23746772]

2. Dewey KG, Adu-Afarwuah S. Systematic review of the efficacy and effectiveness of complementary feeding interventions in developing countries. Matern Child Nutr 2008 Apr;4 Suppl 1:24-85 [FREE Full text] [doi: 10.1111/j.1740-8709.2007.00124.x] [Medline: 18289157$]$

3. Stein AD, Thompson AM, Waters A. Childhood growth and chronic disease: evidence from countries undergoing the nutrition transition. Matern Child Nutr 2005 Jul;1(3):177-184 [FREE Full text] [doi: 10.1111/j.1740-8709.2005.00021.x] [Medline: 16881898$]$

4. Global Targets 2025. World Health Organization. URL: https://www.who.int/nutrition/global-target-2025/en/ [accessed 2020-04-10]

5. Global strategy for women's and children's health 2010. World Health Organization. URL: https://www.who.int/pmnch/ topics/maternal/20100914 gswch en.pdf [accessed 2020-04-10]

6. Center for Health Statistics and Information, Ministry of Health China. An Analysis Report of National Health Services Survey in China. Beijing: Peking Union Medical College Press; Dec 2009.

7. Duan Y, Yang Z, Lai J, Yu D, Chang S, Pang X, et al. Exclusive breastfeeding rate and complementary feeding indicators in China: a national representative survey in 2013. Nutrients 2018 Feb 22;10(2):249 [FREE Full text] [doi: 10.3390/nu10020249] [Medline: 29470415]

8. Spiby H, McCormick F, Wallace L, Renfrew MJ, D'Souza L, Dyson L. A systematic review of education and evidence-based practice interventions with health professionals and breast feeding counsellors on duration of breast feeding. Midwifery 2009 Feb;25(1):50-61. [doi: 10.1016/j.midw.2007.01.006] [Medline: 17418464] 
9. Skouteris H, Bailey C, Nagle C, Hauck Y, Bruce L, Morris H. Interventions designed to promote exclusive breastfeeding in high-income countries: a systematic review update. Breastfeed Med 2017 Dec;12(10):604-614. [doi: 10.1089/bfm.2017.0065] [Medline: 28885859]

10. Skouteris H, Nagle C, Fowler M, Kent B, Sahota P, Morris H. Interventions designed to promote exclusive breastfeeding in high-income countries: a systematic review. Breastfeed Med 2014 Apr;9(3):113-127. [doi: 10.1089/bfm.2013.0081] [Medline: 24568270]

11. Implementation guidelines on national basic public health service program. Ministry of Health China. 2009 Oct 16. URL: http://www.nhc.gov.cn/jws/s3581r/200910/fe1cdd87dcfa4622abca696c712d77e8.shtml [accessed 2020-11-26]

12. Wu Q, Scherpbier RW, van Velthoven MH, Chen L, Wang W, Li Y, et al. Poor infant and young child feeding practices and sources of caregivers' feeding knowledge in rural Hebei Province, China: findings from a cross-sectional survey. BMJ Open 2014 Jul 29;4(7):e005108 [FREE Full text] [doi: 10.1136/bmjopen-2014-005108] [Medline: 25079931]

13. Yue A, Marsh L, Zhou H, Medina A, Luo R, Shi Y, et al. Nutritional deficiencies, the absence of information and caregiver shortcomings: a qualitative analysis of infant feeding practices in rural China. PLoS One 2016;11(4):e0153385 [FREE Full text] [doi: 10.1371/journal.pone.0153385] [Medline: 27073864]

14. Yue A, Zhang N, Liu X, Tang L, Luo R, Yang M, et al. Do infant feeding practices differ between grandmothers and mothers in rural China? evidence from rural Shaanxi Province. Fam Community Health 2018;41(4):233-243. [doi: 10.1097/FCH.0000000000000198] [Medline: 30134338]

15. Fralick M, Haj R, Hirpara D, Wong K, Muller M, Matukas L, et al. Can a smartphone app improve medical trainees' knowledge of antibiotics? Int J Med Educ 2017 Nov 30;8:416-420 [FREE Full text] [doi: 10.5116/ijme.5a11.8422] [Medline: 29200402]

16. Plotnikoff RC, Wilczynska M, Cohen KE, Smith JJ, Lubans DR. Integrating smartphone technology, social support and the outdoor physical environment to improve fitness among adults at risk of, or diagnosed with, type 2 diabetes: findings from the 'eCoFit' randomized controlled trial. Prev Med 2017 Dec;105:404-411. [doi: 10.1016/j.ypmed.2017.08.027] [Medline: 28887192]

17. Gajecki M, Andersson C, Rosendahl I, Sinadinovic K, Fredriksson M, Berman AH. Skills training via smartphone app for university students with excessive alcohol consumption: a randomized controlled trial. Int J Behav Med 2017 Oct;24(5):778-788 [FREE Full text] [doi: 10.1007/s12529-016-9629-9] [Medline: 28224445]

18. Haskins BL, Lesperance D, Gibbons P, Boudreaux ED. A systematic review of smartphone applications for smoking cessation. Transl Behav Med 2017 Jun;7(2):292-299 [FREE Full text] [doi: 10.1007/s13142-017-0492-2] [Medline: 28527027]

19. Schoeppe S, Alley S, Van LW, Bray NA, Williams SL, Duncan MJ, et al. Efficacy of interventions that use apps to improve diet, physical activity and sedentary behaviour: a systematic review. Int J Behav Nutr Phys Act 2016 Dec 07;13(1):127 [FREE Full text] [doi: 10.1186/s12966-016-0454-y] [Medline: 27927218]

20. 6 Powerful WeChat Statistics in 2020 You Need to Know. Brew Interactive. 2020. URL: https://blog.brewinteractive.com/ wechat-statistics [accessed 2020-05-17]

21. Feiran W. WeChat official accounts -an "app-within-an-app” platform. Digital Initiative. URL: https://digital.hbs.edu/ platform-rctom/submission/wechat-official-accounts-an-app-within-an-app-platform/ [accessed 2020-05-17]

22. Zhang X, Xiao H, Chen Y. Evaluation of a WeChat-based life review programme for cancer patients: A quasi-experimental study. J Adv Nurs 2019 Jul;75(7):1563-1574. [doi: 10.1111/jan.14018] [Medline: 30950535]

23. Li W, Han LQ, Guo YJ, Sun J. Using WeChat official accounts to improve malaria health literacy among Chinese expatriates in Niger: an intervention study. Malar J 2016 Nov 24;15(1):567 [FREE Full text] [doi: 10.1186/s12936-016-1621-y] [Medline: 27881122]

24. Cao Y, Lin S, Zhu D, Xu F, Chen Z, Shen H, et al. WeChat public account use improves clinical control of cough-variant asthma: a randomized controlled trial. Med Sci Monit 2018 Mar 14;24:1524-1532 [FREE Full text] [doi: 10.12659/msm.907284] [Medline: 29536984]

25. Feng S, Liang Z, Zhang R, Liao W, Chen Y, Fan Y, et al. Effects of mobile phone WeChat services improve adherence to corticosteroid nasal spray treatment for chronic rhinosinusitis after functional endoscopic sinus surgery: a 3-month follow-up study. Eur Arch Otorhinolaryngol 2017 Mar;274(3):1477-1485. [doi: 10.1007/s00405-016-4371-0] [Medline: 27822702]

26. Dong Y, Wang P, Dai Z, Liu K, Jin Y, Li A, et al. Increased self-care activities and glycemic control rate in relation to health education via Wechat among diabetes patients: a randomized clinical trial. Medicine (Baltimore) 2018 Dec;97(50):e13632 [FREE Full text] [doi: 10.1097/MD.0000000000013632] [Medline: 30558051]

27. He C, Wu S, Zhao Y, Li Z, Zhang Y, Le J, et al. Social media-promoted weight loss among an occupational population: cohort study using a WeChat mobile phone app-based campaign. J Med Internet Res 2017 Oct 23;19(10):e357 [FREE Full text] [doi: 10.2196/jmir.7861] [Medline: 29061555]

28. Wu Q, Huang Y, van Velthoven MH, Wang W, Chang S, Zhang Y. The effectiveness of using a WeChat account to improve exclusive breastfeeding in Huzhu County Qinghai Province, China: protocol for a randomized control trial. BMC Public Health 2019 Dec 02;19(1):1603 [FREE Full text] [doi: 10.1186/s12889-019-7676-2] [Medline: 31791295]

29. General introduction of Huzhu County. Huzhu County Government. 2020. URL: http://www.huzhu.gov.cn/zmhz/hzgk.htm [accessed 2020-07-24] 
30. WHO, UNICEF, USAID, AED, IFPRI. Indicators for assessing infant and young child feeding practices part I: definition. World Health Organization. 2010. URL: https:/www.who.int/maternal child adolescent/documents/9789241596664/en/ [accessed 2020-05-20]

31. Eysenbach G, CONSORT- E. CONSORT-EHEALTH: improving and standardizing evaluation reports of Web-based and mobile health interventions. J Med Internet Res 2011;13(4):e126 [FREE Full text] [doi: 10.2196/jmir.1923] [Medline: $\underline{22209829]}$

32. Meshram II. Impact of feeding and breastfeeding practices on the nutritional status of infants in a district of Andhra Pradesh, India. Natl Med J India 2012;25(4):201-206. [Medline: 23278776]

33. Tang K, Gerling K, Chen W, Geurts L. Information and communication systems to tackle barriers to breastfeeding: systematic search and review. J Med Internet Res 2019 Sep 27;21(9):e13947 [FREE Full text] [doi: 10.2196/13947] [Medline: 31573903]

34. Almohanna AA, Win KT, Meedya S. Effectiveness of internet-based electronic technology interventions on breastfeeding outcomes: systematic review. J Med Internet Res 2020 May 29;22(5):e17361 [FREE Full text] [doi: 10.2196/17361] [Medline: 32469315]

35. Jiang H, Li M, Wen LM, Hu Q, Yang D, He G, et al. Effect of short message service on infant feeding practice: findings from a community-based study in Shanghai, China. JAMA Pediatr 2014 May;168(5):471-478 [FREE Full text] [doi: 10.1001/jamapediatrics.2014.58] [Medline: 24639004]

36. Hegney D, Fallon T, O'Brien ML. Against all odds: a retrospective case-controlled study of women who experienced extraordinary breastfeeding problems. J Clin Nurs 2008 May;17(9):1182-1192. [doi: 10.1111/j.1365-2702.2008.02300.x] [Medline: 18416794]

37. Parry JE, Ip DKM, Chau PYK, Wu KM, Tarrant M. Predictors and consequences of in-hospital formula supplementation for healthy breastfeeding newborns. J Hum Lact 2013 Nov;29(4):527-536. [doi: 10.1177/0890334412474719] [Medline: 23439865]

38. Beyene AM, Liben ML, Arora A. Factors associated with the early termination of exclusive breastfeeding among mother-infant dyads in Samara-Logia, Northeastern Ethiopia. BMC Pediatr 2019 Nov 11;19(1):428 [FREE Full text] [doi: 10.1186/s12887-019-1803-1] [Medline: 31711461]

39. Zhang K, Tang L, Wang H, Qiu L, Binns CW, Lee AH. Why do mothers of young infants choose to formula feed in China? Perceptions of mothers and hospital staff. Int J Environ Res Public Health 2015 Apr 24;12(5):4520-4532 [FREE Full text] [doi: 10.3390/ijerph120504520] [Medline: 25918908]

40. Adams RJ. Improving health outcomes with better patient understanding and education. Risk Manag Healthc Policy 2010;3:61-72 [FREE Full text] [doi: 10.2147/RMHP.S7500] [Medline: 22312219]

41. Bonuck KA, Lischewski J, Brittner M. Clinical translational research hits the road: RCT of breastfeeding promotion interventions in routine prenatal care. Contemp Clin Trials 2009 Sep;30(5):419-426 [FREE Full text] [doi: 10.1016/j.cct.2009.05.005] [Medline: $\underline{19523539]}$

42. Zhang Y, Fan D, Ji H, Qiao S, Li X. Correction: treatment adherence and secondary prevention of ischemic stroke among discharged patients using mobile phone- and WeChat-based improvement services: cohort study. JMIR Mhealth Uhealth 2020 Apr 29;8(4):e19454 [FREE Full text] [doi: 10.2196/19454] [Medline: $\underline{\text { 32348276] }}$

43. Jiang Y, Liu F, Guo J, Sun P, Chen Z, Li J, et al. Evaluating an intervention program using WeChat for patients with chronic obstructive pulmonary disease: randomized controlled trial. J Med Internet Res 2020 Apr 21;22(4):e17089 [FREE Full text] [doi: 10.2196/17089] [Medline: 32314971]

44. Guo Y, Hong YA, Cai W, Li L, Hao Y, Qiao J, et al. Effect of a WeChat-based intervention (Run4Love) on depressive symptoms among people living with HIV in China: a randomized controlled trial. J Med Internet Res 2020 Feb 09;22(2):e16715 [FREE Full text] [doi: 10.2196/16715] [Medline: 32044751]

\author{
Abbreviations \\ CONSORT: Consolidated Standards of Reporting Trials \\ OR: odds ratio \\ SMS: short message service \\ UNICEF: United Nations Children's Fund \\ WHO: World Health Organization
}


Edited by G Eysenbach, R Kukafka; submitted 13.08.20; peer-reviewed by J Huo, C Calyx; comments to author 01.09.20; revised version received 06.09.20; accepted 02.11.20; published 03.12.20

Please cite as:

Wu $Q$, Huang Y, Liao Z, van Velthoven MH, Wang W, Zhang $Y$

Effectiveness of WeChat for Improving Exclusive Breastfeeding in Huzhu County China: Randomized Controlled Trial

$J$ Med Internet Res 2020;22(12):e23273

URL: https://www.jmir.org/2020/12/e23273

doi: $10.2196 / 23273$

PMID: 33270026

(CQiong Wu, Yiwen Huang, Zijun Liao, Michelle Helena van Velthoven, Wei Wang, Yanfeng Zhang. Originally published in the Journal of Medical Internet Research (http://www.jmir.org), 03.12.2020. This is an open-access article distributed under the terms of the Creative Commons Attribution License (https://creativecommons.org/licenses/by/4.0/), which permits unrestricted use, distribution, and reproduction in any medium, provided the original work, first published in the Journal of Medical Internet Research, is properly cited. The complete bibliographic information, a link to the original publication on http://www.jmir.org/, as well as this copyright and license information must be included. 